\title{
Saúde do Trabalhador: Avaliação da Qualidade de Vida no Trabalho de Bancários
}

\author{
SALUD LABORAL: EVALUACIÓN DE LA CALIDAD DE VIDA LABORAL DE EMPLEADOS BANCARIOS
}

\section{Aldo Pacheco Ferreira', Ana Paula Carneiro Carvalho}

1. Fundação Oswaldo Cruz, Escola Nacional de Saúde Pública Sergio Arouca, Departamento de Direitos Humanos, Saúde e Diversidade Cultural, Rio de Janeiro, Brasil.

2. Universidade Federal do Rio de Janeiro, Núcleo de Coordenação de Políticas de Saúde do Trabalhador, Rio de Janeiro, Brasil.

\begin{abstract}
RESUMO
Esta pesquisa buscou avaliar a qualidade de vida no trabalho (QVT) de bancários. Trata-se de um estudo prospectivo, descritivo, exploratório e transversal, com abordagem quantitativa. Foi utilizada uma amostra de conveniência de bancários que atuam em agências localizadas no sítio de estudo (Baixada de Jacarepaguá, Rio de Janeiro/ RJ). Para obtenção dos dados aplicou-se os instrumentos: (a) Questionário do histórico sociodemográfico; (b) Questionário sobre a QVT; e (c) Questionário WHOQOL-Bref. A análise das dimensões por cargos tem os escriturários-caixas com a menor percepção positiva em relação à realização das tarefas completas. Já no esgotamento com o trabalho, em média todos os cargos apresentaram insatisfação. Os dados relativos à avaliação da qualidade de vida dos bancários, denotou um nível baixo, preocupante e significativo no domínio psicológico, pois além da autoestima, contempla outras variáveis, tais como memória, concentração, imagem corporal, aparência e sentimentos negativos. Neste âmbito, torna-se de extrema importância a presença contínua e constante da QVT e a verificação de parâmetros no próprio local de trabalho de cada colaborador para que os seus níveis de desempenho e produtividade sejam positivos.
\end{abstract}

Palavras-chave: SAÚDE DO TRABALHADOR, QUALIDADE DE VIDA NO TRABALHO, BANCÁRIOS

\section{RESUMEN}

Esta investigación tuvo como objetivo evaluar la calidad de vida laboral (CVL) en empleados bancarios. Se trata de un estudio prospectivo, descriptivo, exploratorio y cruzado con un enfoque cuantitativo. Se utilizó una muestra de conveniencia de bancarios que operan en agencias en el sitio de estudio (Baixada de Jacarepaguá, Río de Janeiro / RJ). Para la obtención de los datos se aplicaron los instrumentos: (a) Historia sociodemográfica; (B) Cuestionario sobre CVL; y (c) Cuestionario WHOQOL-Bref. El análisis de las dimensiones por cargos tiene a los cajeros de banco con una menor pecepción positiva en relación a la realización de las tareas completas. En cuanto al agotamiento en el trabajo, en promedio todos los cargos bancarios mostraron insatisfacción. Los datos sobre la evaluación de la calidad de vida de los empleados bancarios, denotó un nivel bajo, perturbados y significativo en el ámbito psicológico, los que además de la autoestima, incluyen otras variables como la memoria, la concentración, la imagen corporal, la apariencia y los sentimientos negativos. En este contexto, es de suma importancia la presencia continua y constante de CVL y parámetros de control en el lugar de cada empleado para que sus niveles de rendimiento y productividad sean positivos.

(Ferreira A, Carneiro A, 2017. Salud Laboral: Evaluación de la Calidad de Vida Laboral de Empleados Bancarios. Cienc Trab. May-Ago; 19 [59]: 128-134).

Palabras clave: SALUD LABORAL, CALIDAD DE VIDA LABORAL, BANCARIOS

\section{INTRODUÇÃO}

0 trabalho tem assumido na nossa sociedade um grande valor, sendo cada vez mais indiscutivel na qualidade e na produção, tomando ampla parte do dia-a-dia dos trabalhadores. Isso significa que hoje o trabalho não consiste apenas em trabalhar por necessi-

\section{Correspondencia / Correspondence:}

\section{Aldo Pacheco Ferreira}

Fundação Oswaldo Cruz, Escola Nacional de Saúde Pública Sergio Arouca, Departamento de Direitos Humanos, Saúde e Diversidade Cultural Avenida Brasil 4036, sala 905. Manguinhos - Rio de Janeiro RJ, Cep: 21.041-361.

Tel.: (21) 3882-9222

e-mail: aldopachecoferreira@gmail.com

Recibido: 05 de Mayo de 2017 / Aceptado 30 de Julio de 2017 dade, mas envolve todo um cenário onde estão incluidos fatores sociais, psicológicos, saúde, satisfação, dentre outros. ${ }^{1,2}$ Considerando a importância de se promover a saúde dos trabalhadores proporcionando dignidade frente aos processos de trabalho, torna-se fundamental observar a situação em que se encontram; haja vista a produção e intensidade das atividades, em geral, através de cobranças caracterizadas por elevadas exigências e, na maioria das vezes, com baixo controle sobre o processo, fruto, em última análise, de uma reestruturação sistemática nas atividades laborais. ${ }^{3-6}$

Segundo Barcelos e Freitas $^{7}$ há uma significante divisão no trabalho bancário: o trabalho operacional, efetivado nas agências e nas centrais de processamento de dados e serviços; e o trabalho administrativo, executado nos departamentos da administração geral do banco. Nesses locais, onde se insere grande parte das funções técnicas, são definidas as políticas gerais do banco e de lá derivam as devidas instruções para a operacionalização nas agências. Têm também dois tipos de banco: o atacadista e o varejista. 
0 primeiro é formado tanto por pessoas jurídicas quanto físicas, desde que movimentem contas com grandes somas de dinheiro. Os chamados bancos atacadistas não possuem muitas agências com número elevado de funcionários, ao contrário, pois seu fim são investimentos no mercado financeiro. Já os varejistas são os mais conhecidos do público em geral, aqueles onde se realizam as operações monetárias do cotidiano, como pagamento de contas, saques, etc.

A Saúde do trabalhador é um campo da saúde coletiva, de grande abrangência em termos de população, território, política, contextos multidisciplinares e interesses políticos e econômicos, entre outros fatores. ${ }^{1,8}$ Sendo assim, busca identificar potenciais relações entre o ambiente, organização, condições de trabalho e os efeitos na saúde do trabalhador, diagnosticando e propondo soluções para os processos relativos à deterioração da qualidade de vida e ao surgimento de doenças relacionadas ao trabalho. ${ }^{5}$ A constatação dos efeitos adversos do ambiente de trabalho requer medidas de promoção e proteção da saúde do trabalhador, mediante desenvolvimento de ações de vigilância dos riscos presentes. ${ }^{8}$

A Qualidade de Vida no Trabalho (QVT) pode ser considerada como um diferencial competitivo, pois ela confirma a importância que os colaboradores têm diante da organização, demonstrando que se deve cultivar a integridade física e mental, considerando os fatores psicológicos, políticos, econômicos e sociais do colaborador. De acordo com Souza; Medeiros $^{9}$ as empresas precisam dos seus empregados como nunca para poder atingir seus objetivos e seus resultados. Principalmente hoje com a pressão e a competitividade geradas pela globalização, a qualidade do produto e o relacionamento empresa-cliente são extremamente importantes.

Em suma, o conceito de QVT compõe-se por múltiplos fatores interdependentes, sendo uma das preocupações centrais das organizações, devido ao seu impacto significativo nos comportamentos dos trabalhadores, nomeadamente no bem-estar. Além disso, é o princípio orientador das políticas de trabalho, na medida em que o trabalhador ao estar satisfeito com o trabalho desenvolve-o com mais eficácia e eficiência, aumentando a sua autoestima e participação no desenvolvimento da entidade, convertendo o trabalho em primeira necessidade da vida. Sendo um elemento fundamental para a sua promoção a possibilidade do trabalhador realizar um trabalho com o qual se identifica e tem vocação e capacidade para o executar. ${ }^{10}$

As relações do trabalho com a saúde, agrupam-se, por conseguinte, as cargas categorizadas como físicas, químicas, biológicas e mecânicas, por um lado, e fisiológicas e psíquicas, por outro. Tal fato, dentro do enfoque histórico e social dos processos biopsíquicos, ressalta que os tipos e intensidades da carga não devem ser considerados de forma isolada, mas vistos dentro de um processo dinâmico que se constrói a cada ambiente ou situação de trabalho. ${ }^{11}$

As questões ligadas ao ambiente de trabalho, à organização, caracterização e condições de trabalho, às oportunidades de desenvolvimento que este permite, ao balanço entre trabalho e vida fora dele, ao envelhecimento da população ativa e à precarização e insegurança no emprego, são, hoje em dia, consideradas fontes de riscos psicossociais. ${ }^{12}$ Sendo assim, o objetivo deste trabalho é analisar a influência de fatores psicossociais e a carga mental no ambiente de trabalho de agentes de trânsito.

Para além das dimensões descritas, as organizações também se veem confrontadas com outros fatores. Conforme destaca Rodrigues ${ }^{10}$, são o aumento da mão de obra qualificada, a elimi- nação de atitudes discriminatórias no contexto de trabalho, o respeito pela dignidade individual, a liberdade de expressão e a aplicação das capacidades e conhecimentos, a segurança no trabalho, a presença de organismos que defendem os interesses dos profissionais, a existência de espaço para a formação e progressão na carreira profissional, a oportunidade de aumentar as qualificações, a concretização dos objetivos individuais e organizacionais, a segurança e saúde do indivíduo no trabalho, o reconhecimento dos resultados concretizados, a participação ativa dos trabalhadores nas tomadas de decisões, a existência de um clima de trabalho sincero, participativo, colaborativo, as boas condições de trabalho e a oportunidade de realização de atividades de lazer.

Esta pesquisa busca avaliação da qualidade de vida no trabalho de bancários, justamente porque ele está no centro do capitalismo financeiro. Nos bancos brasileiros, inúmeras mudanças aconteceram na gestão do trabalho, mas a principal foi a transformação do bancário em um vendedor de produtos. Com isso se desenvolveram técnicas de controle do trabalho como o sistema de metas de produtividade. Este, por sua vez, gerou uma pressão demasiada sobre os trabalhadores e instrumentalizou, dentre outras, o assédio moral como instrumento de gestão. Tal fato provocou o adoecimento da classe trabalhadora constituindo um novo elo entre os dirigentes sindicais e os trabalhadores.

\section{MATERIAL E MÉTODOS}

\section{Tipo de estudo}

Trata-se de um estudo prospectivo, descritivo, exploratório e transversal, com abordagem quantitativa, uma vez que busca conhecer e descrever a percepção e as características comportamentais dos bancários.

A abordagem escolhida para o desenvolvimento da pesquisa deu-se pela sua característica de transformar opiniões e informações em números, com a finalidade de evitar distorções e garantir a precisão dos resultados. A combinação do método prospectivo, descritivo, exploratório e transversal acontece quando se conhece pouco do tema em questão e deseja-se desenvolver: a) estudo quantitativo para quantificar os dados e aplicar a análise estatística; b) abordagem descritiva para se obter melhor visão e compreensão do contexto do problema. ${ }^{13}$

\section{Universo e Amostra}

Para o presente estudo recorreu-se a uma amostra de conveniência e estratificada de bancários com idade entre 20 e 64 anos, de ambos os sexos, que executam as suas funções nas agências localizadas no sítio de estudo (Baixada de Jacarepaguá), em situação ativa, excluindo-se aqueles profissionais ausentes por baixa médica, licença parental, licença sem vencimento ou outro motivo.

\section{Procedimento}

Este estudo recebeu aprovação do Comitê de Ética em Pesquisa com Seres Humanos (15351713.0.0000.5240) (Escola Nacional de Saúde Pública Sergio Arouca). A população do estudo foi composta inicialmente de 97 bancários, que foram convidados a participar voluntariamente do estudo e para tal aceitaram participar da investigação com a assinatura de um Termo de Consentimento Livre e Esclarecido (TCLE). Desse total, 79 bancários responderam ao questionário (81,44\%). Os dados não foram obtidos dos $18,55 \%$ restantes (18 bancários), por estarem de licença ou ausentes de 
suas respectivas funções durante o período de coleta dos dados ou por não quererem participar. A coleta de dados a partir dos questionários foi realizada nas agências bancárias fora do horário de atendimento comercial. Os envelopes contendo os questionários respondidos foram depositados em uma urna lacrada, para que o respondente tivesse total liberdade e para assegurar-se de que as respostas sejam fidedignas. Já as entrevistas foram agendadas via telefone e realizadas em locais combinados estranhos às dependências das agências e também em horário antes ou depois da jornada de trabalho dos pesquisados.

\section{Localização da Área de Estudo}

A baixada de Jacarepaguá se localizada na zona oeste da cidade do Rio de Janeiro com situada a $22^{\circ} 54^{\prime} 24^{\prime \prime}$ S e $43^{\circ} 10^{\prime} 21^{\prime \prime} W$, sendo confinada entre dois maciços a ao sul limitada pelo oceano Atlântico. Possui uma área de 7579,64 ha $\left(75 \mathrm{~km}^{2}\right)$. No censo demográfico apresentou uma população de 100.822 habitantes. ${ }^{14}$ É composta pelos seguintes bairros: Anil, Barra da Tijuca, Camorim, Cidade de Deus, Curicica, Freguesia, Gardenia Azul, Pechincha, Praça Seca, Recreio dos Bandeirantes, Rio das Pedras, Tanque, Taquara, Vargem Pequena, Vargem Grande e Vila Valqueire (Figura 1).

\section{Instrumentos}

Os instrumentos utilizados incluíram (a) Questionário do histórico sociodemográfico; (b) Questionário sobre a Qualidade de Vida no Trabalho; e (c) Questionário World Health Organization Quality of Life/Bref (WHOQOL-Bref).

Figura 1.

Mapa de Localização da baixada de Jacarepaguá/RJ.

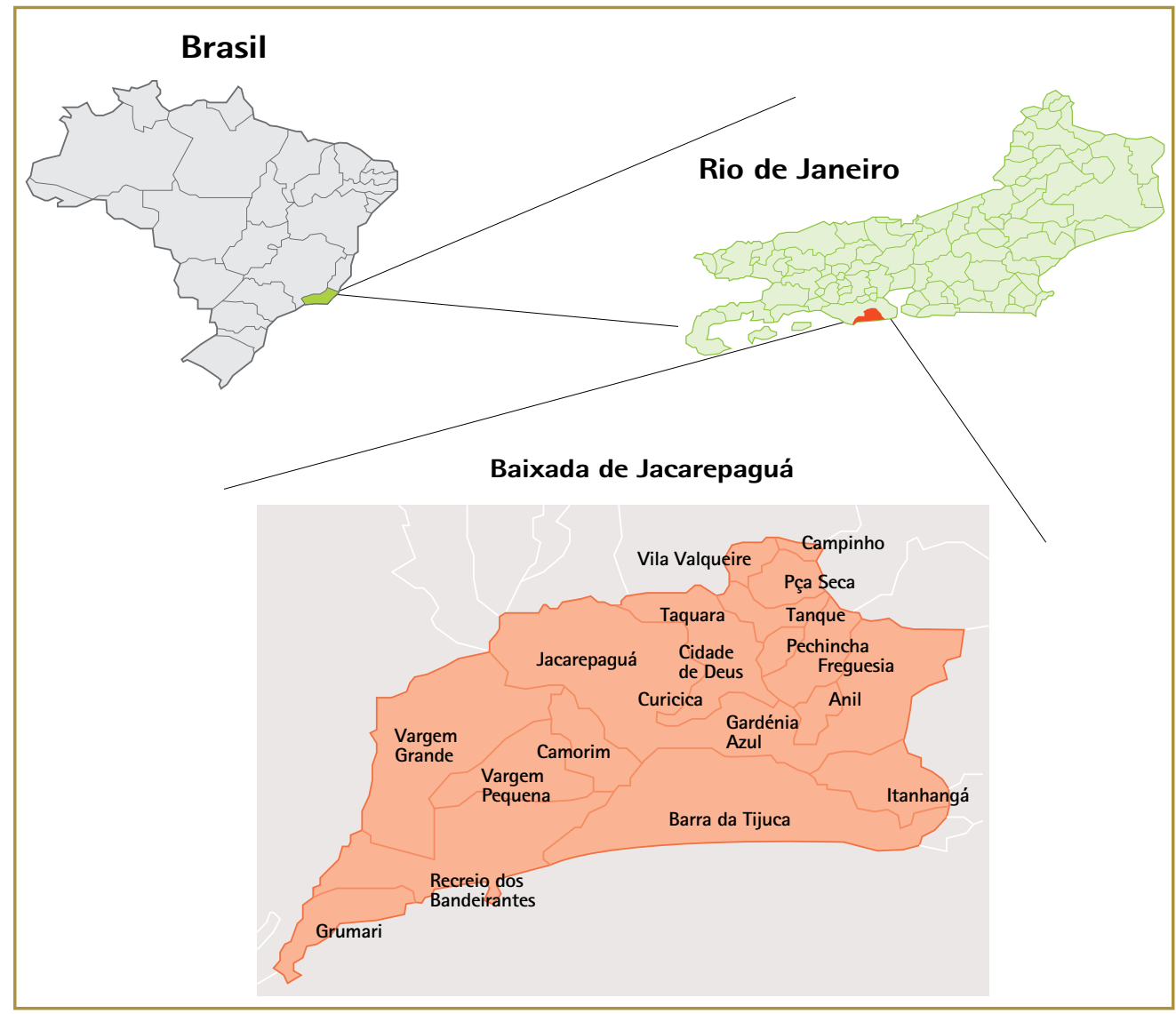

\section{Questionário sociodemográfico}

Instrumento desenvolvido pelos autores, a fim de compreender aspectos sobre a amostra estudada e as questões relativas ao trabalho. Algumas questões sobre a população foram abordadas, como: idade, sexo, estado civil, atividades físicas, escolaridade, tabagismo e atividades laborais. As questões envolvendo o trabalho foram relativas ao cargo, tempo na instituição e no exercício de suas funções, e as atividades mais e menos prazerosas no trabalho. Outras questões foram complementares para averiguar aspectos pertinentes à saúde física e mental e ao trabalho, tais como: questões sobre licenças de tratamento de saúde, mudança de profissão, uso de álcool, psicoativos e/ou drogas ilícitas.

\section{Questionário sobre a Qualidade de Vida no Trabalho}

0 estudo contemplou o uso do questionário estruturado sobre a QVT, desenvolvido por Rafael e Lima15 com 60 itens, o que resultou de análises fatoriais exploratórias e de análises de conteúdo dos itens, de modo a obter-se uma avaliação quer da importância quer da frequência da QVT. Ademais, orientam que especificamente para pesquisas sobre QVT se deve combinar diferentes tipos de fontes de dados. Assim, além da necessidade de triangulação na análise e interpretação dos dados, motivaram a diversidade de fontes os seguintes aspectos: (a) risco de imprecisão nos dados sobre a real situação da qualidade de vida no trabalho da organização, se medidos apenas de forma quantitativa; e (b) possibilidade de que, nas observações das reuniões, os indivíduos enviesem, simplifiquem ou racionalizem pensamentos acerca do construto.

Foram selecionadas cinco grandes dimensões (Emprego [execução do trabalho], Carreira [auto realização], Relações de Trabalho [equidade], Vida Pessoal [relação com a Organização] e Condições de Trabalho [Organização do trabalho]). Esse instrumento foi escolhido por ser um mecanismo que permite mais liberdade ao entrevistador, possibilitando, inclusive, a formulação de novas perguntas.

\section{Questionário World Health Organization Quality of Lifel Bref (WHOQOL-Bref)}

0 WHOQOL-Bref está constituído de 26 questões que abrangem quatro domínios: a) Domínio 1 (Físico):dor e desconforto; - energia e fadiga; - sono e repouso; b) Domínio 2 (Psicológico): - sentimentos positivos; - pensar, aprender, memória e concentração; e - autoestima; c) Domínio 3 (Relações Sociais): relações pessoais; - suporte (apoio) social; e - atividade sexual; e d) Domínio 4 (Meio Ambiente): segurança física e proteção; ambiente no lar; e - recursos financeiros - cuidados de saúde e sociais: disponibilidade e qualidade - oportunidades de adquirir novas infor- 
mações e habilidades - participação em, e oportunidades de recreação/lazer - ambiente físico: poluição/ruído/trânsito/clima - transporte. ${ }^{16}$

Para cada aspecto da qualidade de vida expresso no questionário WHOQOL/Bref, o sujeito pode apresentar sua resposta por meio de escores que variam de um a cinco, sendo a condição pior no escore um e a melhor, no cinco. Os resultados dos domínios apresentam valores entre zero e cem, sendo piores os mais próximos de zero e melhores, os mais próximos de cem. Dessa forma, um sujeito que apresente valor igual a 50 para determinado dominio pode ser considerado mediano para esse domínio. Para verificar a consistência interna da amostra, utilizou-se o coeficiente Alfa de Cronbach. Os domínios e as facetas do WHOQOL/Bref estão descritos no Quadro 1.

\section{Quadro 1.}

Domínios e facetas do WHOQOL/Bref ${ }^{16}$.

Domínio I - Domínio físico
1. Dor e desconforto
2. Energia e fadiga
3. Sono e repouso
Dominio II - Domínio psicológico
4. Sentimentos positivos
5. Pensar, aprender, memória e concentração
6. Autoestima
7. Imagem corporal e aparência
8. Sentimentos negativos
Dominio III - Nivel de Independência
9. Mobilidade
10. Atividades da vida cotidiana
11. Dependência de medicação ou de tratamentos
12. Capacidade de trabalho
Dominio IV - Relações sociais
13. Relações pessoais
14. Suporte (Apoio) social
15. Atividade sexual
Dominio V- Ambiente
16. Segurança fisica e proteção
17. Ambiente no lar
18. Recursos financeiros
19. Cuidados de saúde e sociais: disponibilidade e qualidade
20. Oportunidades de adquirir novas informações e habilidades
21. Participação em, e oportunidades de recreação/lazer
22. Ambiente fisico: (poluição/ruido/trânsito/clima)
23. Transporte
Domínio VI - Aspectos espirituais/Religião/Crenças pessoais
24. Espiritualidade/religião/crenças pessoais

\section{Coleta de dados}

Em um período anterior à coleta de dados foi aplicado um pré-teste com oito bancários, com o intuito de verificar o entendimento das questões e possiveis correções necessárias para a aplicação do questionário. 0 período de coleta foi de março a junho de 2015. A coleta de dados foi realizada em pequenos grupos, nas dependências da própria instituição de trabalho, fora do expediente, adotando-se cuidados adicionais para minimizar os riscos envolvidos na pesquisa com populações vulneráveis, procedendo-se à identificação nos instrumentos somente por códigos estabelecidos aleatoriamente e de acesso exclusivo dos pesquisadores. Foram feitos esclarecimentos necessários ao perfeito entendimento das questões, de forma a não induzir o entrevistado na resposta dada.

As questões abordadas no questionário foram facilmente entendidas e interpretadas pelos respondentes, não sendo necessárias correções, apenas os ajustes de adaptação à atividade profissional pesquisada.

\section{Análise dos dados}

0 nivel de análise da pesquisa é a organização; e a unidade de análise, a qualidade de vida no trabalho dos indivíduos. A perspectiva temporal é seccional, com avaliação longitudinal. Os procedimentos necessários à obtenção de dados envolveram a combinação de formas de coleta, o que normalmente ocorre em estudos de caso, que, por sua vez, se caracterizam pela capacidade de lidar com uma ampla variedade de evidências. Assim, recorreu-se a questionários e observações, que são fontes de evidências para estudos de caso.

A apresentação e a análise dos dados envolveram a utilização de técnicas estatísticas. Procedeu-se ao cálculo das frequências absolutas $(\mathrm{N})$ e percentuais (\%), e medidas de tendência central (Médias). Todas as análises estatísticas foram realizadas no programa SPSS, versão 20.0.

\section{RESULTADOS E DISCUSSÃO}

\section{Análise dos dados demográficos}

A amostra foi constituída por 79 bancários, com as seguintes características: $88,6 \%$ são do sexo masculino e $11,4 \%$ do sexo feminino, com idade entre 20-64 anos; a faixa etária que conta com o maior número de bancários $(35,44 \%)$ é de 30 a 34 anos, sendo que os outros se dividem entre as demais faixas etárias; 30,38\% são solteiros, $63,29 \%$ são casados, e divorciados/separados ou viúvos (6,33\%); quanto a escolaridade, 39,251\% possuem nivel superior, os que possuem superior incompleto cursando ou não, representam 35,44\%. Os pós-graduados são apenas 17,72\% e 7,59\% possuem nível médio; dos trabalhadores inquiridos, 35,44\% referem praticar exercício físico e 64,56\% dos agentes admitem não praticarem exercício físico; $31,64 \%$ dos agentes são fumantes, 48,19\% são não-fumantes e 20,17\% deixaram de fumar; 55,7\% trabalham há mais de dez anos no cargo e 10,12\% há menos de dois anos; 17,72\% realizam outra atividade remunerada; 32,9\% foram ao médico nos últimos seis meses; $17,72 \%$ precisaram se afastar do serviço por motivo de doença; 20,25\% declararam fazer uso de álcool com regularidade e 11,39\% fazem uso de psicoativos.

A diversificação de funções do quadro de pessoal apresentou com a maior concentração representada pelos escriturários-caixas $(n=33$; $41,77 \%)$, seguido pelos gerentes comerciais $(n=19 ; 24,05 \%)$, gerentes operacionais ( $n=15 ; 18,98 \%)$ e supervisão/coordenação $(n=12 ; 15,2 \%)$. Em relação ao tempo de trabalho na organização, a Figura 2 demonstra 27,85\% $(n=22)$ dos entrevistados têm menos de três anos

Figura 2.

Quantitativo dos entrevistados por tempo de trabalho na organização bancária, Rio de Janeiro, 2015.

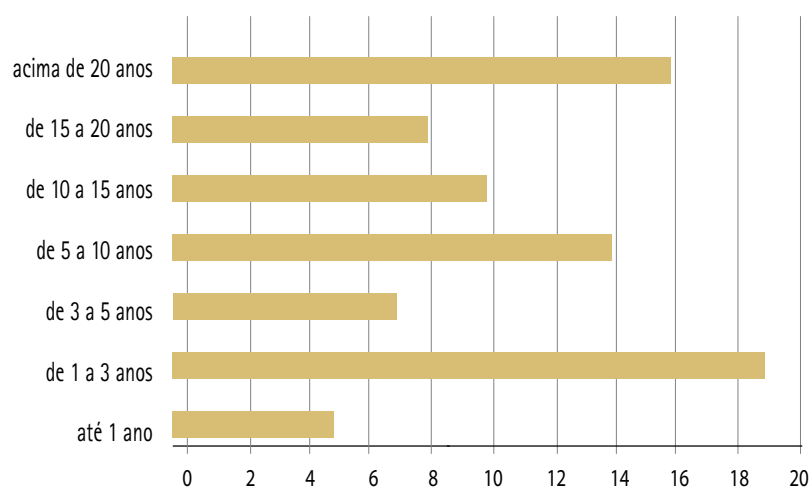


de serviços prestados, 39,24\% (n=31) têm de três a 15 anos de trabalho e 32,91\% ( $n=26)$ têm acima de 15 anos de atuação no setor bancário.

\section{Análise das dimensóes da qualidade de vida no trabalho 1a Dimensão: execução do trabalho}

A avaliação geral foi ligeiramente positiva, com 50,63\% da percepção dos respondentes. A variável realização das tarefas completas foi o ponto crítico dessa dimensão, quando $75,95 \%$ a perceberam de maneira negativa, seguida pela variável esgotamento com o trabalho, que apesar de ter alcançado resultado negativa ficou muito próximo da condição positiva (41,78\% de aprovação).

A análise das dimensões por cargos tem os escriturários-caixas com a menor percepção positiva em relação a realização das tarefas completas, ou seja, 79,75\% veem esse indicador de maneira negativa. Já no esgotamento com o trabalho, em média todos os cargos apresentaram insatisfação, variando o indicador de percepção negativa de $41,78 \%$ a 49,37\%. A Tabela 1 apresenta a primeira dimensão analisada, sendo formada por sete indicadores, expressando a análise da execução do trabalho por cargos.

Tabela 1.

Síntese da avaliação por cargo da dimensão execução do trabalho, Rio de Janeiro, 2015.

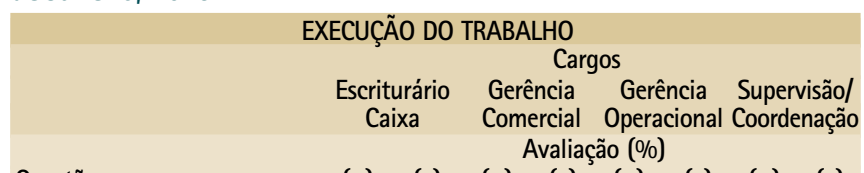

\section{Questão}

Realização das tarefas que parecem simples e corriqueiras

Bom desempenho

na realização das Tarefas

Significância do trabalho

$30,38 \quad 69,62 \quad 18,98 \quad 81,02 \quad 39,24 \quad 60,76 \quad 27,84 \quad 72,16$

$\begin{array}{llllllll}69,62 & 30,38 & 56,96 & 43,04 & 51,9 & 48,1 & 50,63 & 49,37\end{array}$

Realização de tarefas completas $\begin{array}{lllllllll}20,25 & 79,75 & 69,62 & 30,38 & 74,68 & 25,32 & 72,16 & 27,84\end{array}$

$\begin{array}{lllllllllllll}\text { Feedback do trabalho } \quad 88,6 & 11,4 & 93,67 & 6,33 & 78,48 & 21,52 & 74,68 & 25,32\end{array}$

Trabalho não permite uso de

iniciativa e discernimento

$\begin{array}{lllllllll}\text { Esgotamento com o trabalho } & 50,63 & 49,37 & 51,9 & 48,1 & 51,9 & 48,1 & 58,22 & 41,78\end{array}$

\section{2a Dimensão: auto realização}

A segunda dimensão analisada (auto realização), sendo formada por cinco indicadores A dimensão auto realização, que corresponde à satisfação com o trabalho e à realização pessoal e profissional, obteve fator positivo em todos os indicadores, alcançando 60,75\% de aprovação pelos respondentes. A variável oportunidade de desenvolvimento pessoal obteve uma boa avaliação positiva entre os indicadores, com 56,96\%. A Tabela 2 enfatiza os profissionais da gerência operacional com expressivos $74,68 \%$ de respostas positivas para oportunidade de desenvolvimento pessoal e 86,07\% dos representantes da supervisão/coordenação manifestando satisfação com o trabalho. 0 cargo de gerência comercial e de gerência operacional recebem o alerta nessa dimensão, apesar de todos os indicadores exibirem resultados positivos, pois na questão "Conhecimento para realização do trabalho" denotaram o percentual de 51,9\%, sendo os mais próximos do negativo.

3a Dimensão: equidade no trabalho

A dimensão equidade no trabalho quanto a importância da implantação de um plano de cargos e salários teve a maior expressiva avaliação positiva, com 94,94\%. Entre os cargos, a gerência comercial e o de escriturário caixa apresentaram indicador negativo, em
Tabela 2.

Síntese da avaliação por cargo da dimensão auto realização, Rio de Janeiro, 2015.

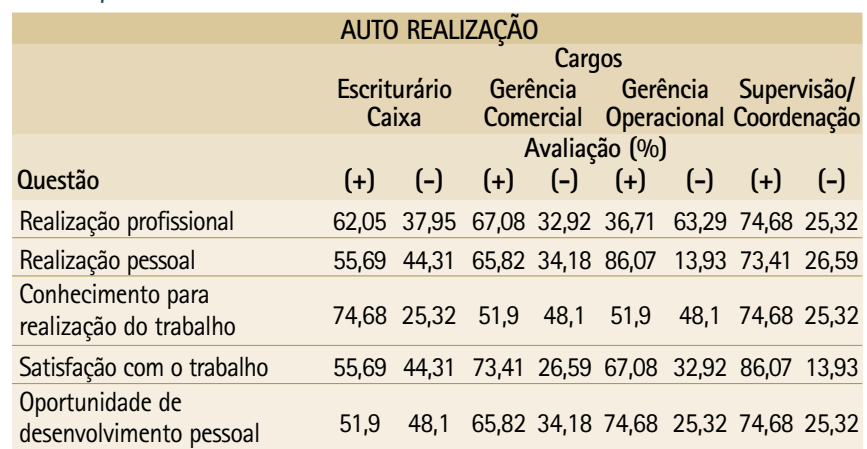

Tabela 3.

Síntese da avaliação por cargo da dimensão equidade no trabalho, Rio de Janeiro, 2015.

\begin{tabular}{|c|c|c|c|c|c|c|c|c|}
\hline \multicolumn{9}{|c|}{ EQUIDADE NO TRABALHO } \\
\hline & & & & Carg & & & & \\
\hline & $\begin{array}{r}\text { Escrit } \\
\mathrm{Ca}\end{array}$ & & $\begin{array}{l}\text { Gerê } \\
\text { Com }\end{array}$ & $\begin{array}{l}\text { ência } \\
\text { ercial }\end{array}$ & $\begin{array}{r}\text { Geré } \\
\text { Opera }\end{array}$ & $\begin{array}{l}\text { ência } \\
\text { acional }\end{array}$ & $\begin{array}{l}\text { Supe } \\
\text { Coord }\end{array}$ & $\begin{array}{l}\text { visão/ } \\
\text { enação }\end{array}$ \\
\hline & & & & Avaliaç & c̃ão $(\%)$ & & & \\
\hline Questão & $(+)$ & $(-)$ & $(+)$ & $(-)$ & $(+)$ & $(-)$ & $(+)$ & $(-)$ \\
\hline $\begin{array}{l}\text { Contar com a ajuda do chefe } \\
\text { quando tiver problemas } \\
\text { no trabalho }\end{array}$ & 25,32 & 74,68 & 44,3 & 55,7 & 93,67 & 6,33 & 94,9 & 5,1 \\
\hline $\begin{array}{l}\text { Relacionamento com colegas } \\
\text { de trabalho }\end{array}$ & 100 & 0 & 88,61 & 11,39 & 74,68 & 25,32 & 100 & 0 \\
\hline $\begin{array}{l}\text { Responsabilidade pelo } \\
\text { trabalho executado }\end{array}$ & 93,67 & 6,33 & 100 & 0 & 100 & 0 & 100 & 0 \\
\hline $\begin{array}{l}\text { Existência de veículos } \\
\text { de informação }\end{array}$ & 74,68 & 25,32 & 86,07 & 13,93 & 86,07 & 13,93 & 100 & 0 \\
\hline $\begin{array}{l}\text { Implantação de plano } \\
\text { de cargos e salários }\end{array}$ & 94,44 & 5,06 & 86,07 & 13,93 & 74,68 & 25,32 & 86,0 & \\
\hline
\end{tabular}

apresentando problemas poder contar com a ajuda do superior (Tabela 3).

Não existe, na literatura, um consenso nem um número definido das dimensões que abordam o conceito de QVT. No entanto, tem-se verificado, com o crescente desenvolvimento econômico, que a compensação e os benefícios deixam de ser os únicos objetivos que os trabalhadores prosseguem. Huang; Lawler; Lei $^{17}$ mencionam que a remuneração deixa de ser suficiente e tão importante para inspirar a lealdade e a satisfação pois a evolução dos valores da força de trabalho indicam que existem mais atrativos que se podem sobrepor, estando os atuais trabalhadores mais interessados em elevar a sua QVT. Além do salário, os trabalhadores esperam obter benefícios nos seus trabalhos como desafios e realização, desenvolvimento de carreira e crescimento profissional, o equilíbrio entre o trabalho e a vida familiar, um clima organizacional harmonioso e suporte por parte da gestão.

\section{4a Dimensão: Relação com a Organização}

Essa dimensão manifesta ótima relação do sujeito com as organizações. A identificação com a missão (88,61\%), a sensação de contribuir para a comunidade $(88,61 \%)$ e o entendimento de que o trabalho realizado contribui para o alcance dos objetivos da organização $(88,61 \%)$ caracterizam forte ligação entre empregado e empregador. Todos os escores médios dessa dimensão foram positivos, porém destaca a imagem externa sob a visão do escriturário caixa $(55,7 \%)$. A análise feita pelos cargos revela os escriturários caixa sinalizando como os únicos a ter visão negativa entre os seis indicadores, seguido 
Tabela 4.

Síntese da avaliação por cargo da dimensão relação com a organização, Rio de Janeiro, 2015.

\begin{tabular}{|c|c|c|c|c|c|c|c|c|}
\hline \multicolumn{9}{|c|}{ RELAÇÃO COM A ORGANIZAÇÃO } \\
\hline & & & & & & & & \\
\hline & $\begin{array}{r}\text { Escrit } \\
\mathrm{Ca}\end{array}$ & $\begin{array}{l}\text { urário } \\
\text { ixa }\end{array}$ & $\begin{array}{l}\text { Gerê } \\
\text { Come }\end{array}$ & $\begin{array}{l}\text { encia } \\
\text { ercial }\end{array}$ & $\begin{array}{l}\text { Geré } \\
\text { Opera }\end{array}$ & $\begin{array}{l}\text { ncia } \\
\text { cional }\end{array}$ & $\begin{array}{l}\text { Supe } \\
\text { Coord }\end{array}$ & $\begin{array}{l}\text { visão/ } \\
\text { nacão }\end{array}$ \\
\hline & & & & Avaliaç & ão $(\%)$ & & & \\
\hline Questão & $(+)$ & $(-)$ & $(+)$ & $(-)^{5}$ & $(+)$ & $(-)$ & $(+)$ & $(-)$ \\
\hline Identificação com a missão & 88,61 & 11,39 & 100 & 0 & 100 & 0 & 100 & 0 \\
\hline $\begin{array}{l}\text { Importância do indivíduo para } \\
\text { que a organização alcance } \\
\text { seu objetivo }\end{array}$ & 73,41 & 26,59 & 94,44 & 5,06 & 74,68 & 25,32 & 100 & 0 \\
\hline $\begin{array}{l}\text { Contribuição do trabalho } \\
\text { para a comunidade }\end{array}$ & 88,61 & 11,39 & 100 & 0 & 100 & 0 & 100 & 0 \\
\hline Imagem externa & 55,7 & 44,3 & 74,68 & 25,32 & 100 & 0 & 100 & 0 \\
\hline $\begin{array}{l}\text { Importância das antigas } \\
\text { histórias de sucesso } \\
\text { da organização }\end{array}$ & 74,68 & 25,32 & 88,61 & 11,39 & 100 & 0 & 100 & 0 \\
\hline $\begin{array}{l}\text { Clareza dos objetivos e } \\
\text { metas do trabalho }\end{array}$ & 74,68 & 25,32 & 74,68 & 25,32 & 100 & 0 & 100 & 0 \\
\hline
\end{tabular}

Tabela 5.

Síntese de avaliação por cargo da dimensão organização do trabalho, Rio de Janeiro, 2015.

\begin{tabular}{lcccccccc}
\multicolumn{7}{c}{ ORGANIZAÇÃo DO TRABALHO } \\
& $\begin{array}{l}\text { Escriturário } \\
\text { Caixa }\end{array}$ & $\begin{array}{c}\text { Gerência } \\
\text { Comercial }\end{array}$ & $\begin{array}{c}\text { Gerência } \\
\text { Operacional }\end{array}$ & $\begin{array}{c}\text { Supervisão/ } \\
\text { Avaliação (\%) }\end{array}$ \\
& $(+)$ & $(-)$ & $(+)$ & $(-)$ & $(+)$ & $(-)$ & $(+)$ & $(-)$ \\
$\begin{array}{l}\text { Questão } \\
\begin{array}{l}\text { Estrutura permite agilidade } \\
\text { nas decisões }\end{array}\end{array}$ & 40,5 & 59,5 & 56,96 & 43,04 & 52,69 & 47,31 & 75,95 & 24,05 \\
\hline $\begin{array}{l}\text { Qualidade da supervisão } \\
\text { recebida }\end{array}$ & 73,41 & 26,59 & 52,69 & 47,31 & 56,96 & 43,04 & 88,61 & 11,39 \\
\hline $\begin{array}{l}\text { Atuação do sindicato } \\
\text { dos bancários }\end{array}$ & 88,61 & 11,39 & 75,95 & 24,05 & 88,61 & 11,39 & 100 & 0 \\
\hline $\begin{array}{l}\text { Existência de comemorações } \\
\text { internas }\end{array}$ & 55,7 & 44,3 & 52,69 & 47,31 & 94,44 & 5,06 & 73,41 & 26,59 \\
\hline $\begin{array}{l}\text { Gestão da organização } \\
\text { competente e democrática }\end{array}$ & 74,68 & 25,32 & 56,96 & 43,04 & 88,61 & 11,39 & 100 & 0 \\
\hline $\begin{array}{l}\text { Existência de equipamentos } \\
\text { adequados }\end{array}$ & 52,69 & 47,31 & 52,69 & 47,31 & 100 & 0 & 100 & 0
\end{tabular}

pelo cargo de gerente comercial em quatro indicadores.

Os respondentes não manifestaram ter dificuldades para enfrentar mudanças no ambiente de trabalho. Reconhecem as instituições onde trabalham como a melhor para se trabalhar, porém não possuem segurança quanto ao futuro na organização. 0 medo de perder 0 emprego é recorrente, podendo afetar o equilíbrio entre vida pessoal e profissional, reconhecendo que todo dia o sistema funcional dos bancos mudam em algo, entretanto ressaltam que as metas não param de ser colocadas e a categoria sente-se 'forçada' a ter que aprender rapidamente. Os supervisores/coordenadores detêm os melhores escores médios dessa dimensão (Tabela 4).

Foi ressaltada pela maioria dos pesquisados a importância do trabalho bancário ter uma jornada diária de $6 \mathrm{~h}$, o que contribuiria significativamente para melhorar a produtividade e diminuir o desgaste ocasionado pelo volume de trabalho, considerado muito superior a jornada exercida.

\section{$5^{\text {a }}$ Dimensão: Organização do trabalho}

Todos os cargos reconhecem que a estrutura da organização não permite agilidade nas decisões. Para a gerência comercial comparada a outros cargos a organização do trabalho apresenta-se como ponto crítico. A Qualidade da supervisão recebida, Existência de comemorações internas e Agilidade nas decisões foi o indicador com mais baixo escore com 52,69\% dos respondes caracterizando-o como ponto positivo. Todos os indicadores foram reconhecidos como positivos, dando destaque para a Gestão da organização competente e democrática e Existência de equipamentos adequados com aprovação de 100\%. Os entrevistados consideraram que os setores da organização atuam em conjunto para alcançarem os objetivos. As atitudes das agências bancárias são coerentes e os processos eficazes (Tabela 5).

Determinados trabalhos sobre QVT foram efetivados com foco no setor bancário, como citam Barcelos; Freitas ${ }^{7}$ e Duarte; Borin; Almeida18, que considerando a importância do setor, que faz parte do setor terciário da economia, nos últimos anos tem representado mais de 60\% do Produto Interno Bruto. Entretanto, percebe-se que os estudos para avaliar a QVT no setor bancário ainda são incipientes, além de não haver um consenso de quais dimensões e indicadores seriam mais adequados para avaliar a QVT no referido setor. Ademais, esses estudos e modelos geralmente se propõem a avaliar a QVT de forma generalizada, muitas vezes não contemplando aspectos relativos à natureza das atividades envolvidas e aos avanços tecnológicos do ritmo de vida contemporâneo.

Huang, Lawler, Lei ${ }^{17}$ mencionam que a decisão em permanecer ou não numa organização depende da capacidade do trabalhador conciliar o seu trabalho com as suas responsabilidades pessoais. Deste modo, o trabalho não pode absorver outras partes da vida do trabalhador, afetando tanto o tempo de dedicação à família, ao lazer e convivência comunitária, como também o seu empenhamento. É fundamental que o trabalhador tenha o seu trabalho e profissão reconhecida assim como igualdade de oportunidades. Neste âmbito, torna-se de extrema importância a presença contínua e constante da QVT e a verificação de parâmetros no próprio local de trabalho de cada colaborador (e.g. condições de trabalho, emprego, carreira, vida pessoal, relações de trabalho, avaliação do desempenho) para que os seus niveis de desempenho e produtividade sejam positivos.

A melhoria da QVT dos bancários pode resultar em uma relação mais harmoniosa com os clientes; e a sociedade também poderá perceber melhorias no atendimento realizado nas instituições bancárias. Duarte, Borin, Almeida18 chamam a atenção para problemas e conflitos entre o bancário e o consumidor, onde sinalizam os consumidores seriam fontes de reconhecimento e pressão para os bancários.

\section{Análise descritiva na aplicaçáo do WHOQOL/Bref}

$\mathrm{Na}$ Tabela 6 apresenta-se os dados descritivos associados aos escores dos domínios da qualidade de vida dos agentes de trânsito. Pode-se verificar que os escores de qualidade de vida tiveram valores médios (em escala de 0 a 100 pontos) de 46,7 pontos para o domínio psicológico, 78,3 pontos nas relações sociais, de 58,5 pontos para o domínio físico, de 59,8 pontos para o domínio meio ambiente e, por fim, 60,3 pontos para a questão global sobre satisfação com a saúde.

No que se refere à consistência interna, o instrumento também obteve valores satisfatórios, indicando que foi alcançada homogeneidade dos itens que compõem os domínios do WHOQOL-Bref de acordo com o ponto de corte recomendado por Babbie, Halley, Zaino. ${ }^{19}$ Os dados encontrados mostram-se relacionados aos achados de Fleck et $\mathrm{al}^{16}$, onde o teste de campo do instrumento original alcançou coeficientes alfa de Cronbach de 0,91 para as 26 questões do instrumento e valores de 0,84, 0,79, 0,69 e 0,71, respectivamente, nos domínios físico, psicológico, relações sociais e meio ambiente. 
Tabela 6.

Dados descritivos da qualidade de vida de agentes de bancários, Rio de Janeiro, 2015, segundo domínios do WHOQOL-Bref.

\begin{tabular}{|c|c|c|}
\hline Domínios (escores de qualidade de vida) & Média & Desvio padrão \\
\hline Domínio Fisico & 58,5 & 9,8 \\
\hline Domínio Psicológico & 46,7 & 11,4 \\
\hline Domínio Social & 78,3 & 12,4 \\
\hline \multirow[t]{2}{*}{ Domínio Ambiental } & 59,8 & 10,6 \\
\hline & 60,3 & 8,2 \\
\hline
\end{tabular}

Os dados relativos à avaliação da qualidade de vida dos bancários (WHOQOL/Bref), denotou um nivel baixo, preocupante e significativo no domínio psicológico, pois além da autoestima, contempla outras variáveis, tais como memória, concentração, imagem corporal, aparência e sentimentos negativos, estando em consonância aos resultados encontrados por Berlim et al20 com pacientes brasileiros com depressão profunda crônica, que mostraram médias similares que as dos bancários.

\section{CONCLUSÕES}

No presente estudo pretendeu-se abordar um tema que se considera ser pertinente e que nos permitisse compreender melhor os aspectos da saúde do trabalhador, avaliando a QVT dos bancários, e ao mesmo tempo permitir alargar os conhecimentos relativamente a um assunto pouco abordado.

Na realidade laboral é reconhecido que o aumento da idade/experiência do trabalhador acarreta tendencialmente uma maior responsabilidade nas funções desempenhadas e percepção de influência, associada muitas vezes a cargos mais elevados na hierarquia organizacional.

Esta pesquisa permitiu verificar o meio ambiente de trabalho dos bancários podem auxiliar na construção de soluções que contribuam com esses profissionais. Além disso, melhores condições de trabalho para os bancários podem se refletir no equacionamento e na melhoria na execução das funções operacionais desta categoria. Igualmente se faz imperioso indicar alguns limites desta pesquisa como o fato de ela ter sido realizada em uma única cidade, o que restringe as possibilidades de generalização de seus resultados. Por outro lado, os limites identificados abrem perspectivas para novas pesquisas que investiguem realidades diferentes para verificar se a relação entre as dimensões da QVT dos bancários permanece a mesma ou se se modifica de região para região, ou de cidade para cidade.

Pesquisa realizada no Departamento de Direitos Humanos, Saúde e Diversidade Cultural, Ensp/Fiocruz, Rio de Janeiro/RJ, Brasil. Projeto sem financiamento.

Os autores negam conflitos de interesse.

\section{REFERENCIAS}

1. Minayo-Gomez C, Lacaz FAC. Saúde do Trabalhador: novas-velhas questões. Ciênc Saúde Coletiva. 2005;10(4):797-807.

2. Santos VO. A vigência da centralidade da categoria trabalho: uma oposição às teorias do fim do trabalho vivo e do fim de sua centralidade. Rev Urutágua. 2009;18:167-175.

3. Buss PM, Pellegrini FA. A saúde e seus determinantes sociais. Physis. 2007;17(1):77-93.

4. Hofmann F, Stöbel U. Occupational health in health care workers. Public Health Forum. 2011;19(3):26.e1-26.e3.

5. Anand $\mathrm{S}$, Bärnighausen T. Health workers at the core of the health system: Framework and research issues. Health Policy. 2012;105(2-3):185-191.

6. Godinho MR, Ferreira AP, Fayer VA, Bonfatti RJ, Greco RM. Capacidade para o trabalho e fatores associados em profissionais no Brasil: Uma Revisão de literatura. Rev Bras Med Trabalho. 2017;15:88-100.

7. Barcelos MRS, Freitas ALP. Qualidade de vida no trabalho no setor bancário: uma análise experimental realizada em Campos dos Goytacazes-RJ. GEPROS. Gest Prod Oper Sist. 2013;8(1):49-65.

8. Minayo-Gomez C, Machado JMH, Pena PGL. Campo da Saúde do Trabalhador: Trajetória, configuração e Transformações. In: Minayo-Gomez C, Machado JMH, Pena PGL., organizadores. Saúde do Trabalhador na Sociedade Brasileira Contemporânea. Rio de Janeiro: Fiocruz; 2011.

9. Souza WJ, Medeiros JP. Diagnóstico da Qualidade de Vida no Trabalho (OVT) de frentistas de postos de combustiveis e suas interfaces com a qualidade dos serviços prestados. REGE Rev Gest. 2007;14(3):71-89.

10. Rodrigues MV. Qualidade de Vida no Trabalho: evolução e análise no nivel gerencial. 13 ed. Petrópolis: Vozes; 2011.
11. Dejours C. Carga psiquica de trabalho. In: Dejours C, Aboucheli E, Jayet C. Psicodinâmica do trabalho: contribuições da escola dejouriana à análise do prazer, sofrimento e trabalho. São Paulo: Atlas; 2010.

12. Costa $L S$, Santos M. Fatores psicossociais de risco no trabalho: Lições aprendidas e novos caminhos. IJWC. 2013;5:39-58.

13. Bussab WO, Morettin PA. Estatística Básica. São Paulo: Saraiva; 2002.

14. Brasil. IBGE. Instituto Brasileiro de Geografia e Estatistica. IBGE Cidades@ [on line]. Brasilia: IBGE; 2017 [acesso Jun 2017]. Disponivel em: http:// www.ibge.gov.br/

15. Rafael M, Lima M. Quality of work life: Findings from a Portuguese study. In: Proceedings XXIX International Congress of Psychology, 2008 Jul 20-25; Berlin, Germany. Berlin: Wiley; 2008.

16. Fleck MPA, Fachel O, Louzada S, Xavier M, Chachamovich E, Vieira G, et al. Aplicação da versão em português do instrumento abreviado de avaliação da qualidade de vida "WHO0OL-bref". Rev Saúde Pública. 2000;34(2):178-183.

17. Huang TC, Lawler J, Lei CY. The effects of quality of work life on commitment and turnover intention. Soc Behav Personal. 2007;35(6):735750.

18. Duarte DV, Borin EC, Almeida M. A Qualidade de Vida no Trabalho: OVT e sua Influência na Vida dos Bancários. Polêmica. 2010;9(4):74-81.

19. Babbie E, Halley F, Zaino J. Adventures in Social Research. Data Analysis using SPSS for Windows. 5th ed. Thousand Oaks: Sage; 2003.

20. Berlim MT, Pavanello DP, Caldieraro M, Fleck PA. Reliability and validity of the WHOQOL BREF in a sample of Brazilian outpatients with major depression. Qual Life Res. 2005;14:561-564. 